\title{
Genuine and false pre-consolidation and yield pressures
}

\author{
Laurence D Wesley ${ }^{1}$ \\ ${ }^{1}$ Retired Civil Engineer, formerly Senior Lecturer at University of Auckland, New Zealand
}

\begin{abstract}
It remains a mystery why the international profession still uses the awkward e-log p plots, and the incomplete and useless coefficient $C_{c}$ which is not even determined from the measured data, but from a constructed line outside the measurements". These are the words of Nilmar Janbu (1998). This paper does not solve the mystery; what it does is highlight the issue behind the mystery in the hope that the profession will face up to the defects of the log scale. An examination is made of oedometer test results when plotted to both scales. Examples are given for sedimentary and residual clays, and sands. It is shown that the e-logp plot routinely produces graphs from which pre-consolidation pressures or yield pressures can be determined. However, when plotted using an arithmetic (linear) scale, this apparent pre-consolidation or yield pressure is found, in most cases, to disappear. It is a false value created by the way the data are plotted. The paper does not deny that pre-consolidation or yield pressures exist in many soils; it gives examples for each of the soil types listed above. It is recommended that the term "yield pressure" be used in preference to "preconsolidation pressure", and that only the use of a linear scale will reveal whether such a pressure exists.
\end{abstract}

\section{Introduction}

Soil mechanics is a recent addition to the field of civil engineering, having only become known worldwide in the 1930s. It grew rapidly in the following decades and by about 1960 a firm theoretical framework had been established on which to base its further development. Along with this theoretical framework various empirical correlations and assumptions were adopted, many of which have proved valid and have survived to this day. Some, however, have survived without being subject to the sort of scrutiny they deserved. An important example is the continued use of the $\log$ scale to portray soil compressibility. Nilmar Janbu [1] has pointed this out over the years, and has written

"It remains a mystery why the international profession still uses the awkward e-log p plots, and the incomplete and useless coefficient $\mathrm{C}_{\mathrm{c}}$ which is not even determined from the measured data, but from a constructed line outside the measurements".

A brief history of the use of the log plot is given followed by examples of errors resulting from its use, and a preferred portrayal of soil compressibility is proposed.

\section{History of the log scale}

The earliest graphs of void ratio versus pressure for one dimensional compression appear to be those of Gilboy [2] shown in Figure 1, adapted and reproduced by Terzaghi and Peck [3] in their book "Soil Mechanics in Engineering Practice". These curves are for a mixture of sand and mica, and are similar to those from soft remoulded clay. The linear and log pressure scales give dramatically difference impressions of the behaviour of the material. The linear scale (curve a-b) shows that the material becomes progressively stiffer as the pressure increases, in accordance with intuitive expectations. As the particles become more tightly packed the material becomes stronger. When re-plotted to a log scale, the reverse impression is created. The soil appears stiffer at a low stress and then "yields" and becomes of uniform compressibility.
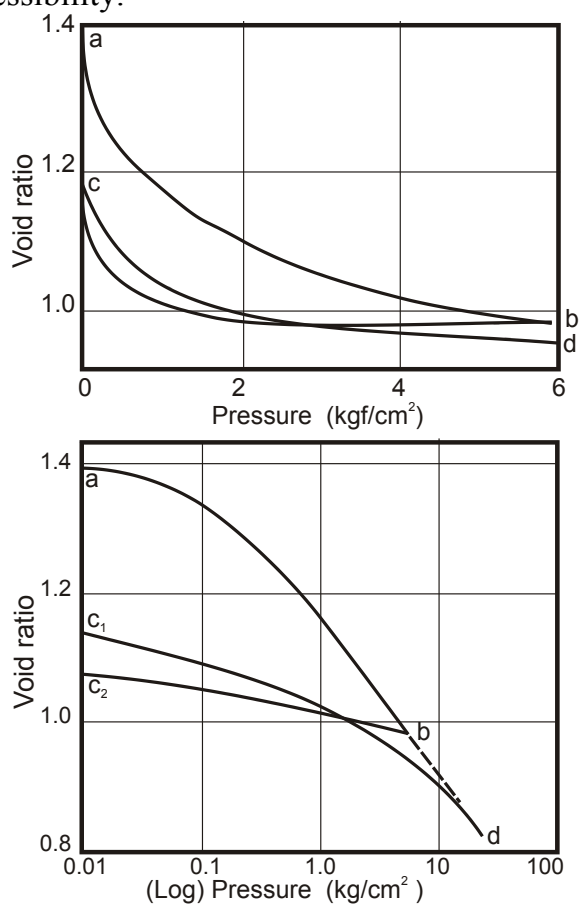

Fig. 1. Void ratio versus pressure for sand-mica mixtures (after Terzaghi and Peck, [3]).

Figure 1 is presented in Terzaghi and Peck [3] along with the results of tests on clays. In each case the results are 
shown using both linear and log scales. These authors state that when a natural (linear) scale is used the graph is an e-p graph and when a log scale is used it is an e-logp graph. The parameters applicable to each pressure scale are described, that is, $\mathrm{m}_{\mathrm{v}}$ and $\mathrm{C}_{\mathrm{c}}$ for the linear and $\log$ scales respectively.

In the same year that Terzaghi and Peck's book was published, a second significant and influential book appeared, namely Soil Mechanics, by D.W.Taylor [4]. Figure 2 is taken from that book and shows a void ratio versus pressure relationship from a clay sample plotted using both a natural and a log pressure scale. Taylor points out that above $4 \mathrm{~kg} / \mathrm{cm}^{2}$ the graph is linear in the log plot and its slope is used to define the log parameter $\mathrm{C}_{\mathrm{c}}$. The possible use of a parameter defined in terms of the natural scale is not discussed.
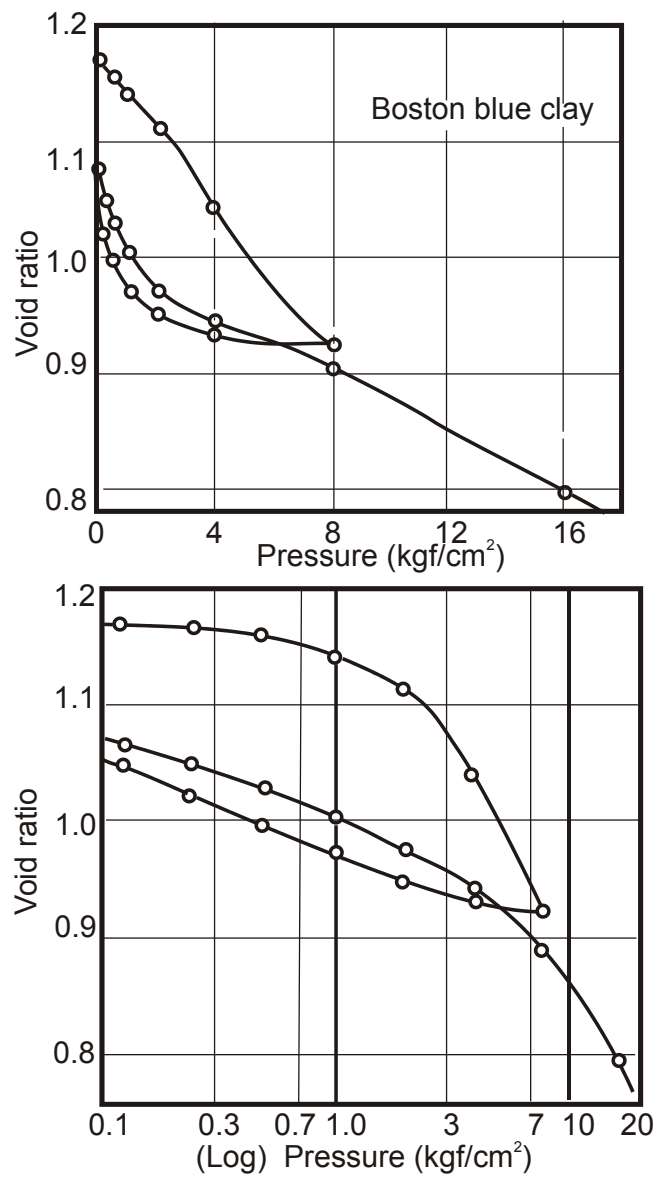

Fig. 2. Void ratio versus pressure for a clay (after Taylor,[4]).

Most text books from 1943 to the present day focus primarily on e-logp graphs, and the use of the log parameters $C_{c}$ and $C_{s}$ for settlement estimates. We will now look at results of tests on a range of soils.

\section{Examples of log and linear plots}

\subsection{Virgin consolidation from a clay slurry.}

Figure 3 shows the results of an oedometer test on a clay taken from a site in Auckland, New Zealand. It was initially prepared as a slurry and allowed to settle in a large container about $25 \mathrm{~cm}$ in diameter. It was then

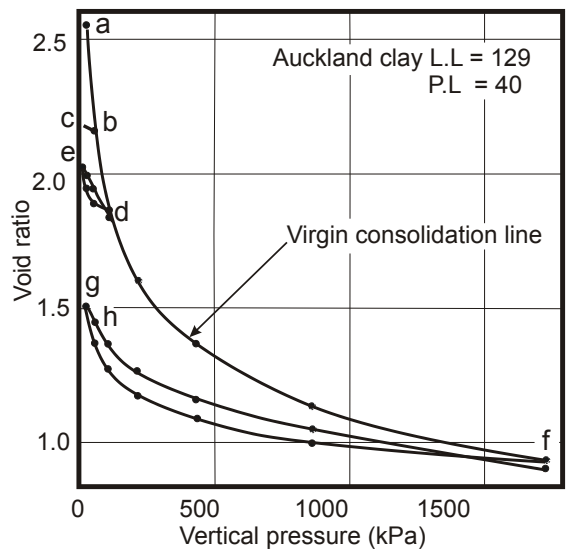

(a) linear scale

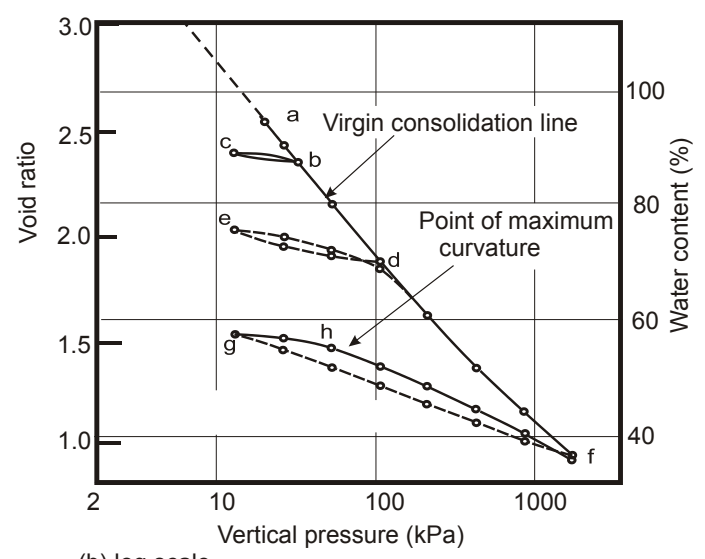

(b) log scale

Fig 3. Consolidation from a clay slurry.

allowed to consolidate under a series of small load increments until firm enough for a sample to be taken from it for a conventional oedometer test. Three unloading and re-loading cycles were involved in the oedometer test as shown in Figure 3. The line above point $\mathrm{b}$ is somewhat approximate as the initial recordings were not very precise.

The important points to be noted are the following:

(1) The virgin consolidation line is very close to linear on the log plot

(2) The slope of the unloading and re-loading lines becomes steeper as the pressure level rises

(3) The change in slope at the point where the re-loading line meets the virgin consolidation line becomes less clear as the pressure increases.

(4) An examination of the re-loading line g-h-f shows that at point $f$ its gradient is almost the same as the virgin consolidation line. In other words, at the intersection point the re-loading curve is asymptotic to the virgin consolidation line.

(5) It is apparent from this behaviour that the preconsolidation pressure is not clearly defined at high stresses. The re-loading line g-h-f actually has its maximum curvature at point $\mathrm{h}$ rather than at the intersection with the virgin consolidation line. 


\subsection{Young, normally consolidated, clay}

Typical results of oedometer tests on a young marine clay are shown in Figure 4. The samples are from a site near Butterworth in Malaysia. The upper graph shows conventional behaviour for such clay with well defined pre-consolidation pressures. The lower graph clearly confirms their existence. These pre-consolidation pressures are about 1.5 times greater than the in situ effective vertical pressure, which is common in such clays. Ageing with time tends to create weak bonds between the particles which make the soil stronger.
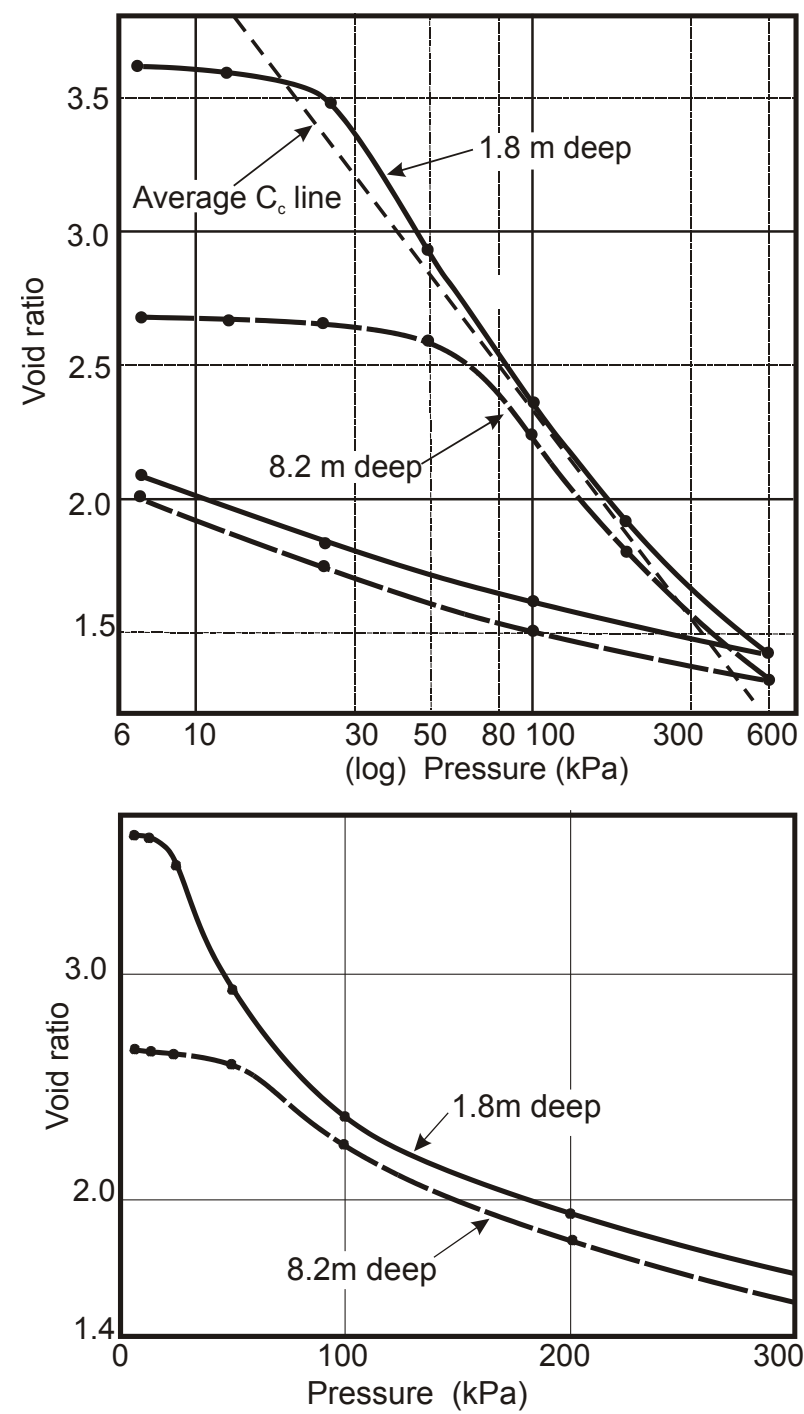

Fig. 4. Oedometer tests on young normally consolidated marine clay in Malaysia (from Wesley and Richards, [5]).

\subsection{Over-consolidated clay}

Figure 5 shows the results of an oedometer test on an over-consolidated clay taken from a site in Auckland, New Zealand. Normal interpretation from the upper graph with the log scale is likely to be the existence of a pre-consolidation pressure of about $500 \mathrm{kPa}$. The lower graph shows no evidence whatsoever that this is the case.
These graphs illustrate the statement made by Janbu [1] quoted above.

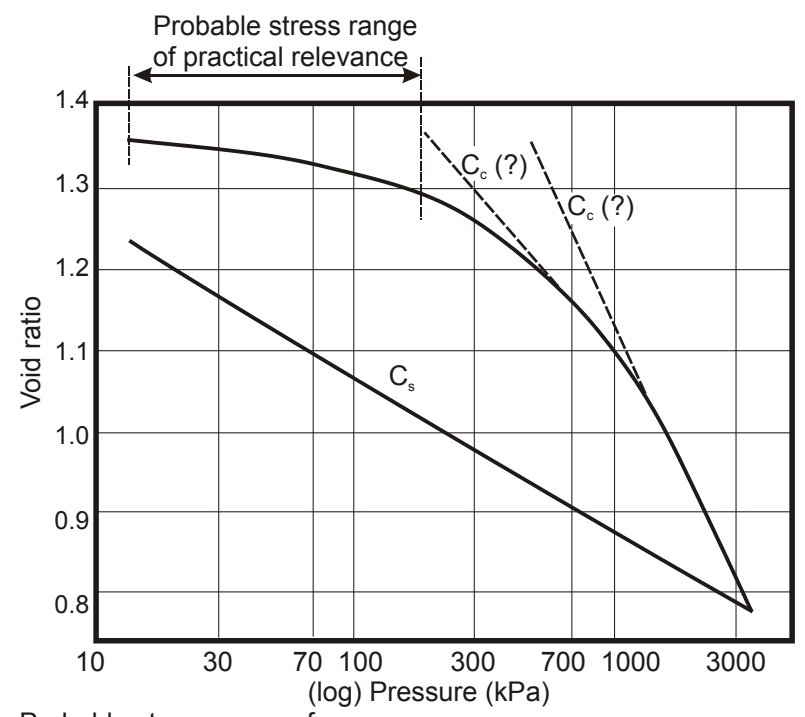

Probable stress range of

practical relevance (almost linear)

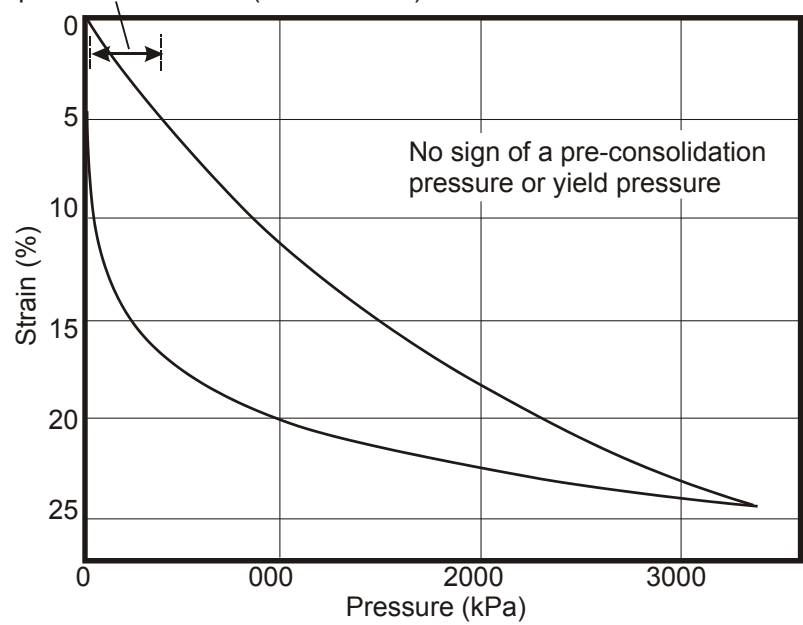

Fig. 5. Oedometer tests on an over-consolidated clay from Auckland, New Zealand.

As Janbu points out, the value of the compression index $\mathrm{C}_{\mathrm{c}}$ is regularly determined from tangent lines largely outside the measured data. The parameter $\mathrm{C}_{\mathrm{c}}$ thus determined is of no practical value at all for the following reasons:

a) Its value depends on the stress level to which the test is taken. Many oedometer tests are only taken to a stress of $700 \mathrm{kPa}$ to $1500 \mathrm{kPa}$ and even at the latter stress the graph may not clearly show linear behaviour.

b) The value of $\mathrm{C}_{\mathrm{c}}$ determined in this way is for a stress range unlikely to be relevant to practical situations.

c) The lower graph with an arithmetic scale shows an initial portion that is approximately linear over the stress range likely to be of interest in foundation design, in which case use of the linear parameter $\mathrm{m}_{\mathrm{v}}$ would be much more appropriate. 


\subsection{Residual clay}

An example of the application of concepts from sedimentary soil behaviour to residual soils is shown in Figure 6. The upper graph with the log scale has been used to determine pre-consolidation pressures and the over-consolidation ratios (OCRs) listed. With a linear scale it is clear that these OCRs are fictional and reflect only the way the data are plotted and the erroneous application of a conventional soil mechanics procedure.
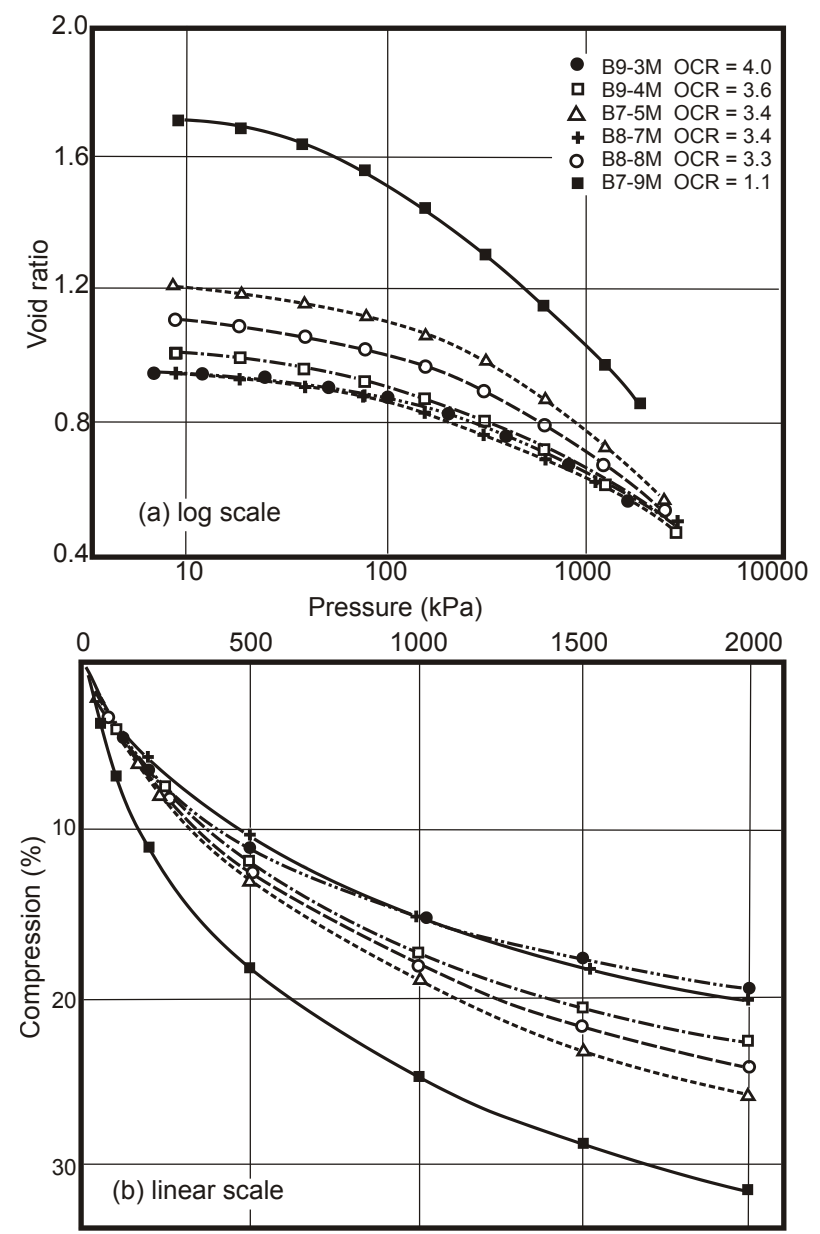

Fig. 6. Oedometer tests on Piedmont (USA) residual soil (after Wesley, [6]).

Residual soils occupy at least half of the world's surface and yet their existence is largely ignored in conventional soil mechanics. It is long past the time when residual soils can be regarded as a special group at the edge of "normal" soil mechanics. Residual soils should be an integral part of routine soil mechanics. An obvious reason for this is that illustrated in Figure 6 which occurs routinely with residual soils. The use of the compression index $\mathrm{C}_{c}$ is another example. This parameter is the slope of the virgin consolidation line defined with reference to the e-logp graph.

Research papers on residual soils often give values of their "compression index". This is clearly incorrect as they are not formed by a consolidation process so whatever is determined is not related to virgin consolidation. Similarly, pre-consolidation pressures are quoted for residual soils when their properties are governed by the chemical processes that formed them and not from their stress history.

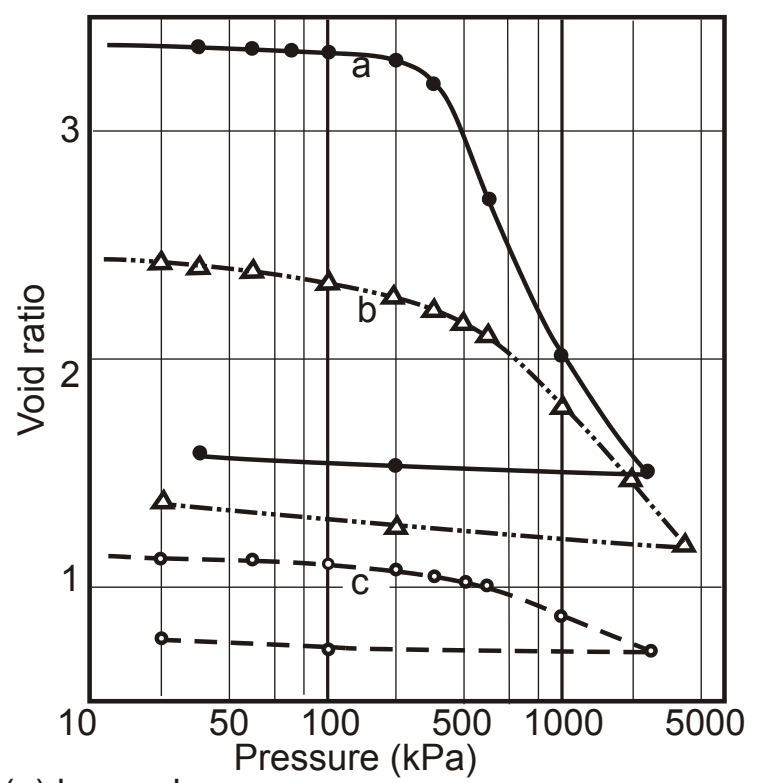

(a) $\log$ scale

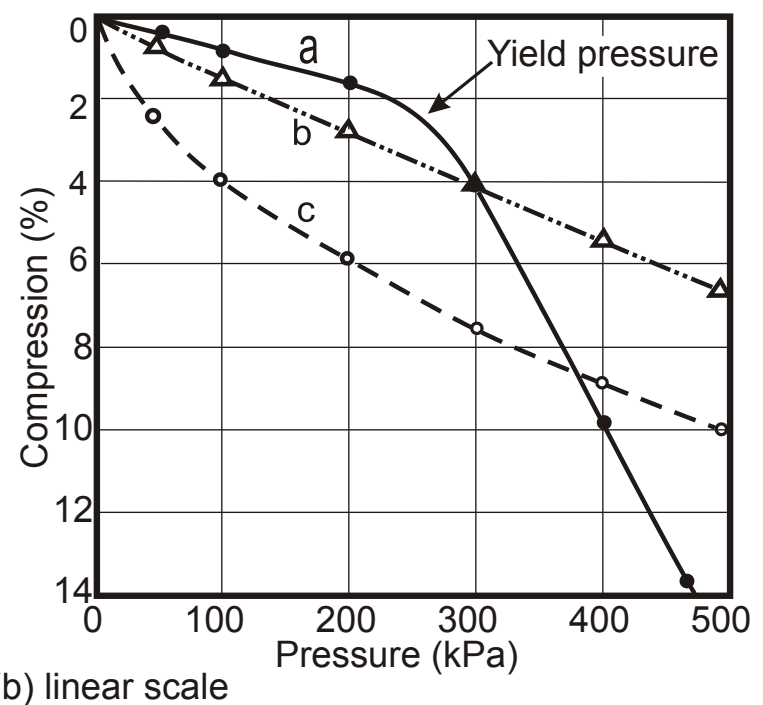

Fig. 7 Oedometer tests on volcanic ash clays

Clays derived from the weathering of andesitic volcanic ash show distinct variations of compression behaviour as illustrated in Figure 7. Andesitic volcanic eruptions are characterised by large quantities of fine ash which in successive eruptions is deposited as layers in the surrounding countryside. Each layer is of slightly different chemical composition and is exposed at the surface for different periods of time. For these reasons the layers do not have identical properties.

Plotted in the conventional way with a log scale, the curves are of similar shape although their void ratios are very different. This illustrates a serious defect of the log plot, namely that it creates the impression that the compression behaviour of all soils is the same. When plotted to a linear scale it becomes clear that the three samples exhibit quite different behaviour. Sample a shows a clear increase in compressibility at a pressure of about $250 \mathrm{kPa}$. Sample b shows almost constant 
compressibility and Sample c shows steadily decreasing compressibility, or is "strain hardening". For Sample a the pressure at which there is a marked increase in compressibility should be termed a yield stress, since it is clearly not a pre-consolidation pressure

\subsection{Sand}

This paper is primarily concerned with clays and only some brief observations will be made on the behaviour of sand, in particular the following:

(1) The compression behaviour of sand under one dimensional loading is significantly different from that of natural clays. Most natural clays have an in situ structure which is an important influence on their compression behaviour, whereas with sands structural influence is much less significant.

(2) There is not a sound basis, either theoretical or empirical for using a log pressure scale to portray the compression behaviour of sand.

(3) Particle crushing plays a significant role in their behaviour, especially at high pressures, but is not a significant factor in the behaviour of clays.

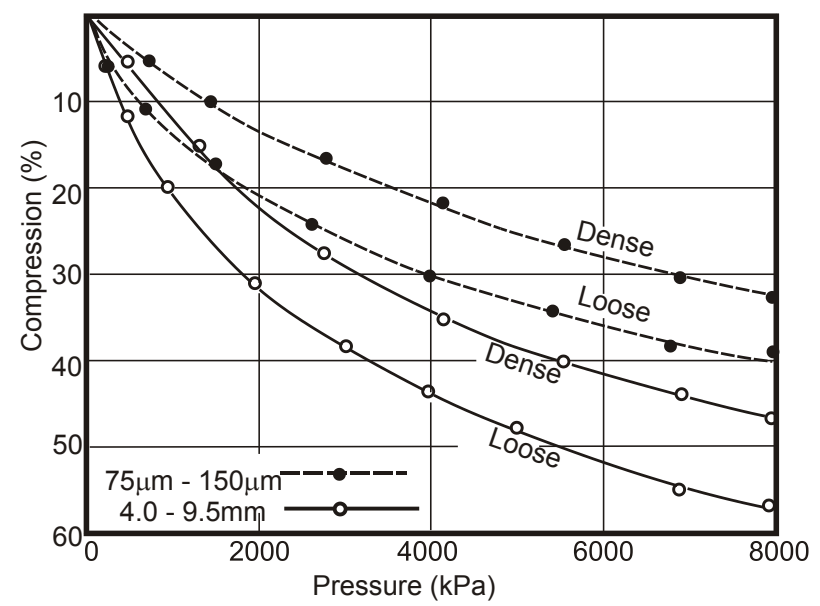

Fig. 8 Oedometer tests on a soft grained pumice sand of varying particle size (Wesley, [7]).

Various attempts have been made to identify yield pressures in sand and relate them to the crushing strength of the particles, as for example, is done by Hyde and Nakata [8]. The use of the log scale has led to the identification of yield pressures which are not verified using a linear scale. There is, however, a relationship between particle strength and yield pressure which, at least at first sight, is somewhat surprising. The relationship is illustrated in Figures 8 and 9.

Figure 8 shows oedometer tests carried out on a sand consisting almost entirely of pumice particles. The grains are very light and weak due to their vesicular nature. Prior to testing the sand was sieved to obtain the fine and a coarse grained fractions indicated in the figure. The graphs show no evidence of a yield stress. Measurements of particle size before and after the tests showed that particle crushing began at quite low stresses and occured progressively. There is thus no sudden onset of crushing, and no yield stress

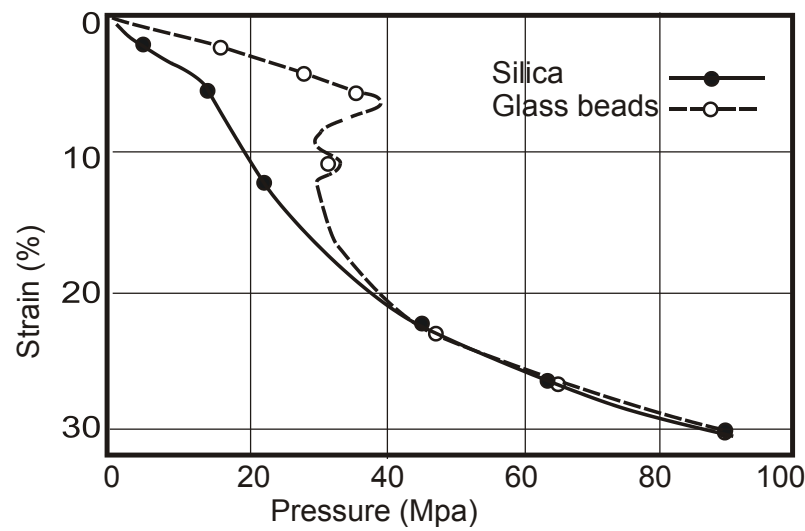

Fig. 9 Oedometer tests on hard grained quartz sand and glass beads (Hyde and Nakata, [8])

Figure 9 illustrates the results of similar tests carried out on hard grained materials using a special oedometer capable of very high stresses. The two materials tested were a silica sand and glass beads (bellotini). Both materials were of similar particle size and were prepared in the oedometer with an initial void ratio of 0.6 . Tests were taken to a maximum pressure of $90 \mathrm{MPa}$. Both graphs show a yield pressure, but it is far more pronounced with the glass beads than the silica sand.

The glass beads show a very sudden collapse, so rapid that the vertical stress could not be maintained and declined significantly before rising again. There appears to be a sudden breakage of one bead which transfers stress to other beads and a chain reaction follows, resulting in a substantially finer and denser material. With the silica sand the process occurs at a substantially lower stress and is more gradual. The conclusion from this is that soft grained sands are very unlikely to show a yield stress, but hard grained soils of uniform grading may do so.

\section{Further considerations}

An important issue in understanding compression behaviour is soil structure. Many, if not most, soils are sensitive to some degree due to the elimination of their in situ structure by remoulding, Thus when soil is compressed, as for example in an oedometer test, two things are happening:

(a) The soil particles are being forced closer together and making the material denser, or more compact. This can be expected to make the soil stronger and less compressible.

(b) Any structure the soil had in its original state is steadily being destroyed as the stress level increases. This can be expected to weaken the soil and make it more compressible.

The compression behaviour of the soil thus depends on which of these two influences predominates. Non structured soils are likely to become steadily stiffer as the stress increases, while structured soils are likely to yield and soften when the structure begins to crumble. 
A further important point regarding oedometer tests is illustrated in Figure 10, which shows the results of two oedometer tests on soft clay reported by Dobie [9]. For the first test the normal loading procedure is followed in which each load doubles the stress However, as pointed out by Dobie, this can easily result in poor definition of the yield (pre-consolidation) pressure as the points may lie on either side of the stress zone critical for accurate determination. Figure 12 also shows a test on the same soil carried out with a different loading sequence, with closely spaced points up to a stress level higher than the yield pressure. This clearly enables a more reliable estimate of the yield stress to be made.

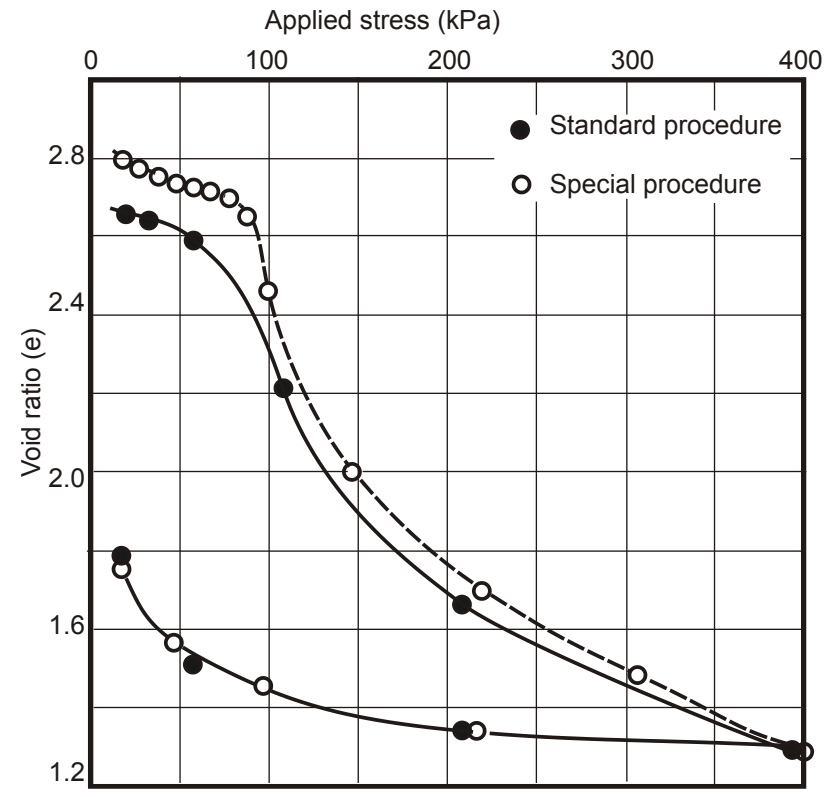

Fig. 10. Oedometer tests on a soft clay with different loading sequences (after Dobie, 2016)

\section{Conclusion}

1) The use of the e-logp graph for portraying soil compressibility has been shown to have many shortcomings. The principal ones are:

a) It fails to give a true picture of soil compressibility and creates the impression that it is basically the same for all soils.

b) Pre-consolidation pressures determined using the Casagrande method are often non-existent when the data are re-plotted using a linear pressure scale.

c) The log plot has no relevance whatsoever to residual soils.

2) Only in the case of soft normally consolidated sedimentary clays is there a valid reason for using the e-logp plot and the $\log$ parameter $\mathrm{C}_{\mathrm{c}}$ for settlement estimates. For all other soils the linear plot and the linear parameter $\mathrm{m}_{\mathrm{v}}$ are far more appropriate.

3) The conventional portrayal of soil compressibility using a log scale should be replaced with that shown in Figure 11 This gives an accurate portrayal of the range of compressibility behaviour encountered in natural clays over the stress range normally encountered in geotechnical engineering.

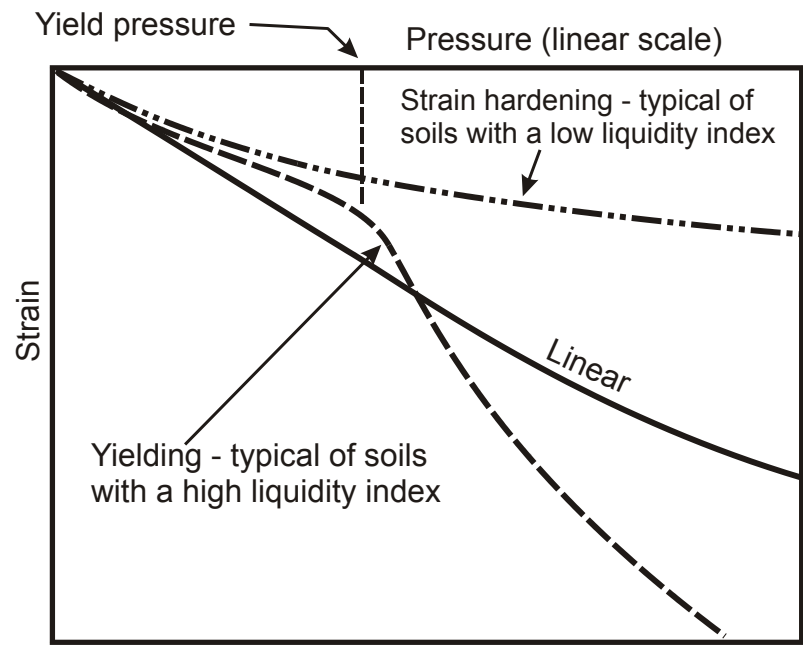

Fig. 11. A preferred portrayal of soil compressibility

\section{References}

1. N. Janbu, Sediment deformation. Bulleting 35, Norwegian University of Science and Technology, Trondheim, Norway, (1998)

2. G. Gilboy, The compressibility of sand-mica mixtures. Proc. American Society of Civil Engineers, 54, pp 555-568. (1928)

3. K. Terzaghi, R.B. Peck, Soil Mechanics in Engineering Practice, 2nd Edition, pp 67-68. John Wiley, New York (1943)

4. D.W. Taylor, Soil Mechanics. pp217-218. John Wiley, New York (1943)

5. L.D. Wesley, B.A. Richards, Preloading and wick treatment of a very soft clay site at Prai, Malaysia. Proc. Fifth Int. Geot. Seminar Case Histories in Soft Clay, Singapore (1987)

6. L.D. Wesley, Discussion on paper: Influence of in situ factors on dynamic response of Piedmont residual soils. ASCE Journal of Geotechnical and Geoenvironmental Engineering. Vol 126, No 4, 384385 (2000)

7. L.D. Wesley Geotechnical characteristics of a pumice sand. Proc. Characterisation and Eng. Props. of Natural Soils. Singapore. Vol. 4 pp 2449-2473. Taylor and Francis. (2007)

8. A.F.L. Hyde and Y, Nakata, Yield and Soil Crushability Proc. Int. Workshop on Soil Crushability, Ube, Japan, pp 1-18. (1999)

9. M. Dobie, On the Pre-consolidation Pressure: Experience Based on Testing the Holocene Marine Clay of Peninsula Malaysia. Geot. Eng. Journal of the SEAGS \& AGSSEA Vol. 47 No. 4 (2016) 